\title{
A Case Report of the Dental Quackery in a 42 year old Male Patient
}

\section{Fareedi Mukram Ali ${ }^{1}$, Roshan Uthappa ${ }^{2}$, A.P Nirmal Raj ${ }^{3}$, Sanajay Kumar ${ }^{4}$}

${ }^{1}$ Reader, Dept of Oral \& Maxillofacial Surgery, College of Dental Sciences \& Hospital, Amargadh, Gujrath, INDIA

${ }^{2}$ Professor, Dept of Conservative Dentsitry \& Endodontics, College of Dental Sciences \& Hospital, Amargadh, Gujrath, INDIA

${ }^{3}$ Dean \& HOD, Dept of Prosthodontics, College of Dental Sciences \& Hospital, Amargadh, Gujrath, INDIA

${ }^{4}$ Dept of Prosthodontics, College of Dental Sciences \& Hospital, Amargadh, Gujrath, INDIA

\begin{abstract}
Dental quackery describes the misinterpretation of the diagnosis and treatment of the dental disease. Most commonly dental quacks are the self-styled experts, whose basic tools are very incompetent and also fraud. It is prevalent in India since many decades. Many dental quacks are practicing roadside, which makes money by doing unethical practice and ultimately hampering patient's oral health. It is thus challenge to the dental practitioners to fight against dental quackery. Hereby, the article describes a case report of dental quackery in 42 year old male patient.
\end{abstract}

Key words: Quackery, Quacks, Roadside dentists, Unconventional dentists

12/31/2015
How to Cite: Ali FM, Uthappa R, Raj AP and Kumar S. (2015) A Case Report of the Dental Quackery in a 42 year old Male Patient Malaysian Journal
of Medical and Biological Research, 2(2), 55-58.
$\begin{aligned} & \text { This article is is licensed under a Creative Commons Attribution-NonCommercial 4.0 International License. } \\ & \text { Attribution-NonCommercial (CC BY-NC) license lets others remix, tweak, and build upon work non-commercially, and although the new works must also CC) } \\ & \text { acknowledge \& be non-commercial. }\end{aligned}$

\section{INTRODUCTION}

As in the other fields of the medicine, dentistry is also a science based and highly regulated health care profession. It serves increasingly sophisticated and demanding patients. Nowadays, dentistry is facing numerous challenges; one of the most important is the dental quackery. It is also called as road-side dental treatment or street dentistry.3,11,2

Due to this unethical practice of the quackery, the patient's oral health is in danger, as many complications can arise after such practice. As a dental practitioner, it is our responsibility to stop this dental quackery practice. The present article describes a case of dental quackery in a 42 year old male patient.

\section{Case Report}

A 42 year old patient came to the department with a quack denture placed in the mandibular right posterior region replacing the mandibular first molar. Acrylic impinging on the gingiva at the lower and lateral borders and the loss of the embrasures in between contact of the teeth was present. Also one irregular metal wire was placed at the buccal gingival margin of the mandibular second premolar, which also causing irritation of the gingiva and inflammation was noted at the site. (Fig. 1)

\section{FIGURES}

Fig. 1: Intraoral photograph showing replacement of the missing mandibular molar done by the quack dentist

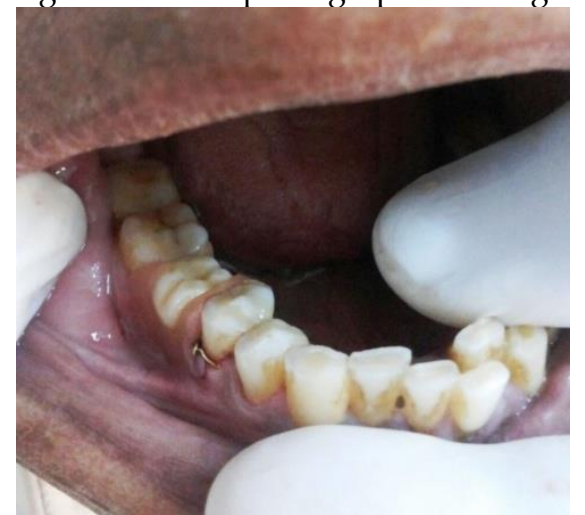

Fig. 2: Figure showing the procedure of the removal of the quack denture 


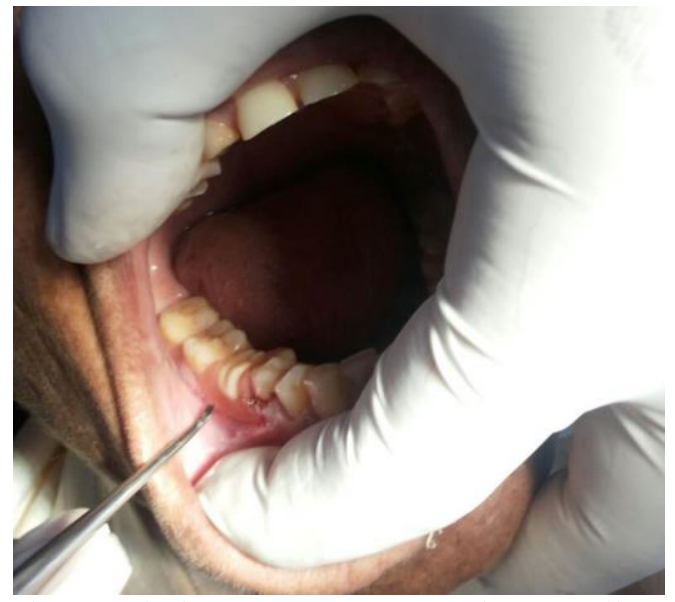

The quack denture was removed surgically (Fig. 2) with the help of instrumentation and with the precautions of not to damage the adjacent teeth and the gingiva. The removed quack denture had very irregular and sharp margins and the tooth used for the replacement was also not showing the proper anatomical details. (Fig. 3 and 4 )

Fig. 3: Removed quack denture.

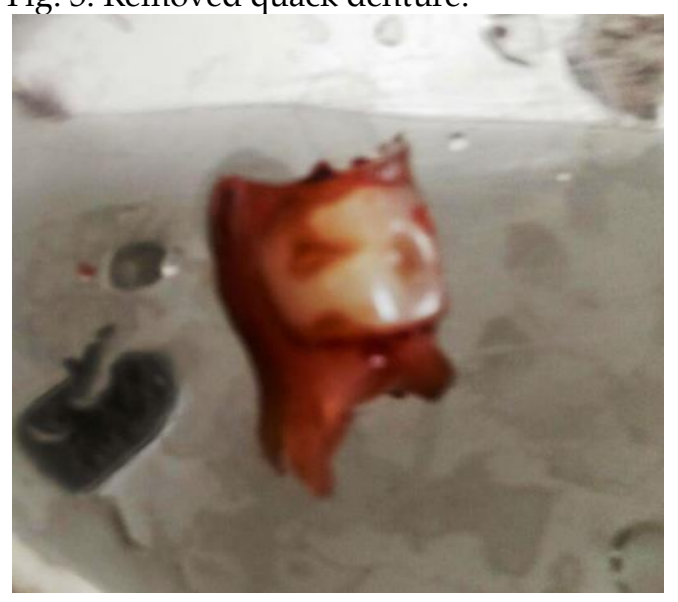

Fig. 4: After cleaning of the removed quack denture. Note the sharp edges and irregular metal wire.

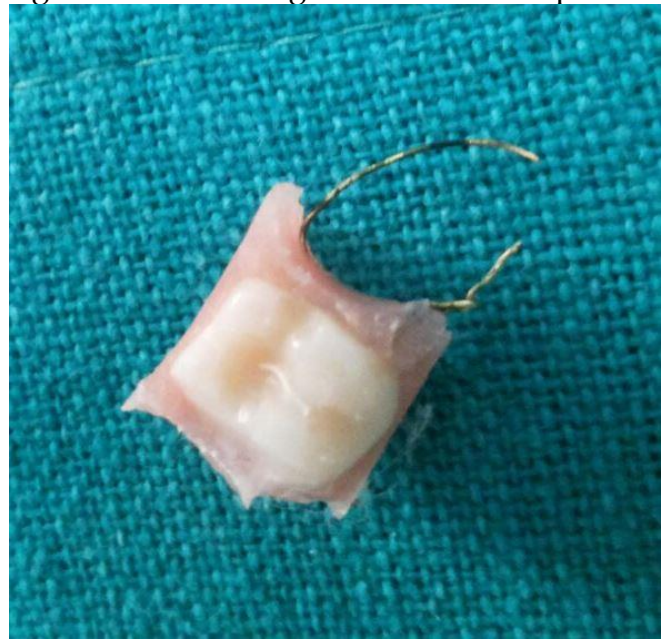

Patient was prescribed antibiotics and analgesics to reduce the inflammation. Follow-up of the patient was done after 1 week and thereafter 2 weeks. After complete healing of the site, fixed prosthesis was given to the patient to replace the missing tooth. 


\section{Discussion}

The term "Quackery" is derived from the word quacksalver i.e. the person who boasts his salves. 12 Quackery can be defined as "the fraudulent mis-representation of one's ability and experience in the diagnosis and treatment of disease or of the effects to be achieved by the treatment offered." 9

Quacks are the persons who have observed and learnt themselves the techniques of the dental treatment. They learn these procedures while assisting dental surgeons or these may be inherited from their families and they adopted it as a profession. 9

Quack can also be defined as "the person who misrepresents their ability and experience in the diagnosis and treatment of the particular disease or effects to be achieved by their treatment." 12

Quacks are untrained persons and basically do not have the scientific professional education in the field of the practice.12 Also their tools are usually incompetence and fraud.11

\section{REASONS FOR THE QuACKERY}

There are numerous reasons for the implement of the quacks in the society like: 11,17,2,12

- When trained and competent practitioners are in short supply

- When their charges appears prohibitive to a segment of the population.

- Absence of the basic primary health care approach in dentistry.

- Lack of awareness.

- Poor patient: dentist ratio in the population.

\section{Practice of Quackery}

The quackery in dental treatment can be done in various forms like use of self cure acrylic resins for fixing and replacing the teeth, frequent use of the suction discs for achieving retention in dentures, usage of the single anesthetic needle on multiple patients and remnants of the tooth roots after extraction. 9

\section{HARMFul EfFEcts of Dental Quackery}

Dental quack is characterized by a lack of sufficient knowledge and effectiveness for diagnosis, treatment or prevention in concern with the dental treatment. Also quacks lacks valid scientific base. Thus the dental quackery can lead to various harmful effects like:

- Placement of suction disc can lead to erosion of the palatal mucosa.

- Fixed denture with self cure acrylic can lead to erosion of the gingiva, bone loss or loss of adjacent tooth.

- The use of unsterilized instruments can lead to transmission of life threatening infections.

- It can result in unnecessary root canal treatment of the involved teeth.

- Some dental quacks advices the use of direct application of 30\% hydrogen peroxide to remove stains on teeth, which has harmful effect on pulp tissue like obliteration of odontoblasts, hemorrhage, resorption and inflammatory infiltration.

- It can lead to misdiagnosis and/or incorrect treatment for serious and potentially life-threatening Diseases.30

\section{CONCLUSION}

Quackery is practicing dental treatment from the last many decades. Nowadays, modern quacks are the salesman and they play on fear. Many of the quacks are doing their procedures by roadside and making money from the dental treatments, which are harmful for the patients. Thus it is high time for the dental practitioners to fight against the quackery for the health of the patients and also importantly to save this prestigious profession.

\section{REFERENCES}

Naidu RS, Gobin I, Newton JT. Perceptions and use of dental quacks (unqualified dental practitioners) and self rated oral health in Trinidad. International Dental Journal 2003; 53(6):447-54.

Goyal S, Kansal G, Deepika. Quackery in dentistry: An overview. Journal of Dental Peers 2013; 1(2):150-7.

Nagarajappa S, Mohapatra AK. Street dentistry: Time to tackle quackery. Indian J Dent Res 2009; 20(1):1-2.

Khan AS, Syed A, Qureshi A, Ijaz S, Khan AA. Evaluation of problems related to malpractice and professionalism in Islamabad area - a study. Pakistan Oral \& Dent Jr 2004;24(1):74-6.

De Silva D, Gamage NT. Unqualified dental practitioners or quacks in Sri Lanka. Sri Lanka Dental Journal, $2011 ; 41(03): 46-51$.

Kamboj M, George J. Quackery- Mockey: Dentistry. Dent Poster J 2013;2(4):3.

Rastogi J, Rastogi S, Prasant MC, Mulani SS. Dental quackery- Challenge to dentistry: A review. European Journal of Biomedical and Pharmaceutical Sciences 2014;1(3):349-52.

$$
\text { --0-- }
$$


